\title{
108 エレベーター向け画像応用防犯センサ*
}

\author{
林 健太郎 (三菱電機), ○関 真規人 (三菱電機), 塩崎秀樹 (三菱電機ビルテクノサービス) \\ 文屋 太陽 (三菱電機), 森 光正 (三菱電機), 濱地 浩秋 (三菱電機)
}

Visual Sensor in Elevator for Crime-Prevention

\author{
Kentaro Hayashi, Mitsubishi Electric Co., Makito Seki, Mitsubishi Electric Co., \\ Hideki Shiozaki, Mitsubishi Electric Building Techno-Service Co., \\ Akira Fumiya, Mitsubishi Electric Co., \\ Mitsumasa Mori, Mitsubishi Electric Co., and Hiroaki Hamaji, Mitsubishi Electric Co.
}

\begin{abstract}
This paper presents a new critical event detection method simplified for an embedded appliance mounted on an elevator car. We first define that the critical event is unusual action such as violent action, counteraction, etc, and introduce the violent action degree(VAD). We use an optical flow based method to analyze the current state of the motion through an ITV(Industrial Television) camera. After motion analysis, we calculate a normalized statistical value, which is the VAD. The statistical value is the multiple of the optical flow direction variance, the optical flow magnitude variance, and optical flow area. Our method calculates the statistical value variance and normalize it by the variance. At last we can detect critical event by thresholding the VAD. In addition, we should detect persons and objects staying in an elevator for a long time. For this purpose, we apply texture background subtraction method. Our violent action detection method detects $80 \%$ of critical events where at most $6 \%$ of false acception and object detection method detects $99 \%$ where about $1 \%$ of false acception.
\end{abstract}

Key Words : elevator, ITV camera, crime-prevention, optical flow, texture background subtraction

\section{1.はじめに}

Table1 は，日本エレベータ協会が 2000 年から 2003 年に発

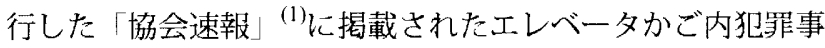
例の，筆者らによる分類結果である. 犯罪件数は 37 件あり， そのうち加害者が殴る/踭るなどの暴力゙をふるったり，被害 者が抵抗したりした犯罪は 18 件 (約半分) あった. 本論文で はこうした犯罪行為や，事故につながる閉じ込めを検知する 手法について述べる. 具体的には当事者の暴力や抵抗動作 (こ れを暴れと呼ぶ)をリアルタイムで検出し，また人物の有無 を高精度で検出するエレベーター用組込み画像応用システム について述べる。

動画像からの人物動作解析に関するこれまでの研究では， 主に人物に取り付けたマ一カや身体の一部を特徵点として検 出し，時空間的に追跡するアプローチが採られてきた ${ }^{(2)}$. な かには，スデレオ視を利用することで，人物の服装や照明条 件への碩健性を高めたものもある ${ }^{(3)}$. しかし，一般的に，工 レベーターを利用する不特定多数の人にマーカを取り付ける ことや，狭いエレベーターかご内で特定部分が常に見えるよ うにカメラを配置することは難しい，また，このようなセグ メンテーションを伴うミクロ的手法を高速・高精度に実現す るには，高価なハードウェアリソースと多数のパラメータ調 整が必要となり，組込みシステムにとっては望ましくない(4). 人物動作をマクロ的にとらえる手法には，動画像の時空間

原稿受付平成 17 年 11 月 25 日

1 对物の突き付け，絞首，羽交締めなど，動きの少ないものは除く，
Table 1 Crime type analysis. Number of crimes from 2000 to 2003.

\begin{tabular}{|c|c|c|c|c|c|}
\hline \multirow[t]{2}{*}{ crime type } & \multicolumn{4}{|c|}{ type } & \multirow[t]{2}{*}{ total } \\
\hline & $\mathrm{A}^{\dagger}$ & $\mathbf{B}^{\dagger}$ & $\mathrm{C}^{\dagger}$ & $\mathrm{D}^{\dagger}$ & \\
\hline robbery with violence & 10 & & 1 & & 11 \\
\hline robber & & 4 & & 11 & 15 \\
\hline grabber & & 1 & & 2 & 3 \\
\hline murder & & & & 2 & 2 \\
\hline immorality & 1 & & & 2 & 3 \\
\hline trick & & 1 & & & 1 \\
\hline fire & & & & 2 & 2 \\
\hline total & 11 & 6 & 1 & 19 & 37 \\
\hline
\end{tabular}

${ }^{+} \mathrm{A}$ is violence by assailant, $\mathrm{B}$ is resitance by victim, $\mathrm{C}$ is violence and registance, $\mathrm{D}$ is unknown.

エッジ特徴を DP マッチングする方法がある(5). また，画像 上のオプティカルフローにより動き特徴を抽出し，隠れマル コフモデル $(\mathrm{HMM})$ で認識を行った研究がある(6).これらの 手法は，人物の服装や照明条件の变化に左右されにくく，多 クラスの識別問題が扱える点で有效である。ただし，背景物 体の動きに刘しては課題が残っており，空付きエレベーター などでは使えない。

一方エレベーターかご内における人物の有無は，人物の出 現によって生じる画像上の変化を捉えることによって判断す ることができる，これを実現する代表的な方法としては背景 差分法がよく知られている，背景差分法は背景画像と入力画 像との喗度值を比較することで，効率よく変化領域を抽出す 
る方法であるが，空付きエレベーターでは人物の出現以外に 外界の日照変化によっても画像が変化するという問題がある.

そのような照明条件が変化する環境下で背景差分を実現す るために，画像上の輝度の空間的な分布形状(テクスチヤ)に 着目した方法が提案されている(7)(8). なかでも, 松山ら ${ }^{(8)}$ は, テクスチャの変化とその変化の空間的な一様性を評価する頑 健な背景差分 (以下ではテクスチャ背累差分と呼ぶ)を実現し た. そこで, 本研究では，このテクスチャ背景差分を採用し， 人物有無検知への適用を図る.

本論文では，エレベーターへの組込みを目的に，オプティ カルフローの統計量をマクロに評価する暴れ検出アルゴリズ ムと，閉じ込めなどを検知するのに必要となる人物有無を検 知するアルゴリズムを提案する．提案手法では，平常時の人 物動作は単調であるが，暴れ動作は，上記の組み合わせより も複雑であると仮定し, 画像全点で求めたフローベクトルの 向きと大きさのばらつき，抽よび個数を評価することで，暴 れ動作か否かの 2 クラス識別問題を簡便に解く．また人物の 有無は, エレベーターの照明の変化や空付きエレベーターで の外光の影響に碩健な，テクスチャ背景差分方式を用いて高 精度に検知する.

以下では，まず暴れ動作時のフローにばらつきが見られる ことを示し，その後暴れ検知アルゴリズムを示す. 次にエレ ベーター内の照明変化について述へ，これに適する人物有無 検知アルゴリズムを示す．最後に，犯罪模擬映像に対する暴 れ検知結果, および通常乗降時の人物有無検知結果を示して 提案システムの有効性を明らかにする。

\section{2. フローのばらつき}

本論文では，人物の服装や照明条件の変化に左右されにく いマクロな特徵量を得るために, 画像全点でのオプティカル フローを用いる. オプティカルフローは，画像上の各点にお ける移動量と方向を表したもので，時間的に連続した画像間 の対応点を探索することで求められる.

ここで Fig.1 に示すエレベーターのかご内映像を用いて， 暴れ動作時のフローにばらつきが見られることを検証する. そのため, 典型的なフロー検出手法のひとつの SAD(Sum of Absolute Difference) ブロックマッチングによりフローを算出 し, フローベクトルの向き (8 方向) と大きさ (4 段階) のヒス トグラムを求めた。 まず，平常時と暴れ動作時 ${ }^{2}$ のる瞬間に おけるヒストグラム例をそれぞれ Fig.2 の (a),(b) に示す.こ れらの図を比較すると, 平常時のフローには偏りがあり, 逆 に，暴れ動作時のフローにはばらつきがあることが分かる.

また，これらフローのばらつき度合を標準偏差值として求 め, (平均的なばらつきで正規化した後) 所定時間区間におい てプロットしたものを Fig. 3 に示す．縦軸が向きのばらつき 度合，横軸が大きさのばらつき度合を表している．図を見る と，暴れ動作時には平常時に比べ，向きのばらつきと大きさ のばらつきが共に大きい場合がある．暴れ動作中のすべての 時間において，この大きなばらつきが観測されるわけではな いが，ばらつき度合を評価していれば，少なくとも，ばらつ

2役者を雇い，犯罪事例を再現した．詳細は 5 章で述べる．

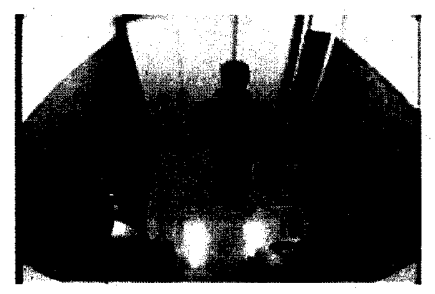

(a) Usual

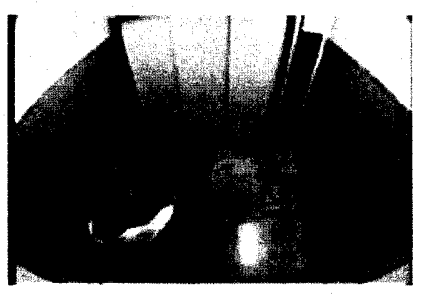

(b) Violent action
Fig. 1 ITV camera images in a non-window door elevator car.

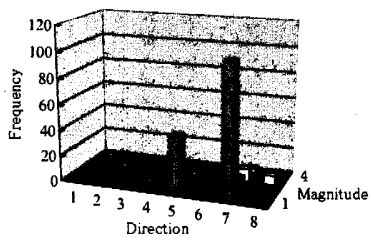

(a) Usual

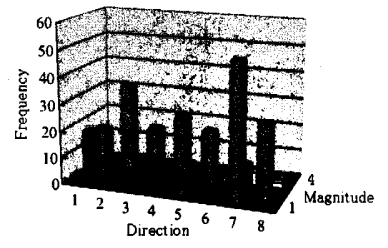

(b) Violent action
Fig. 2 Histogram of optical flows at usual and violent action.

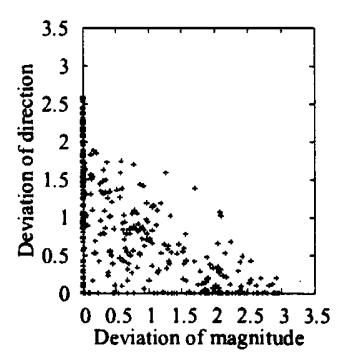

(a) at usual

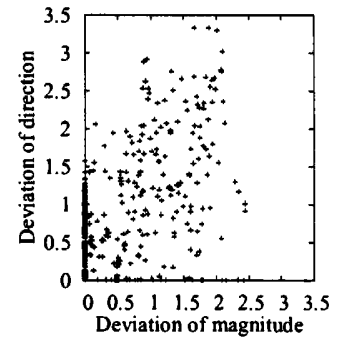

(b) when violent action occurs
Fig. 3 Standard deviation of optical flow when usual and violent action occurs.

きが大きな瞬間に暴れを発見することができると考えられる． 提案手法では，この「向きのばらつき」と「大きさのばら つき」を暴れ検出の評価尺度とする．また，絶対的な動きの 量に制限を設けるために,「フローの個数」を尺度に加え， 3 つのマクロな統計量により暴れを判定することにした。

\section{3. 暴れ検知アルゴリズム}

エレベーターかごにはさまざまな意匠がある，壁の色・模 様, 空の有無, 照明の明るさ, 大きさの違いなどがある. ま た, 監視カメラが取り付けられる位置もかご毎に異なってい る. 前章で示した結果は, これら意匠やカメラ位置が異なっ ても概ね同様の結果となるが，その全体的な傾向は，かご毎 に変わってしまう，そこで本アルゴリズムでは, 統計量をか ご毎に正規化して暴れを判定する. 以下ではこのようなかご の違いを考慮した暴れ検出アルゴリズムを示す.

3.1 学習本アルゴリズムでは，まず，平常時における フローの統計量をモデル化する. 具体的な学習アルゴリズム は以下のようになる。

1. 学習用に用意された画像間の全点で, SAD ブロックマッ チングによりフローベクトルを求める. その際, マッチ ングレベルの低いフローは破棄する. 
2. 大きさが非零のフローベクトルに対し，3つの統計量を 求める。すなわち,「向きのばらつき $D 」$,「大きさのばら つき $M 」$ ， および「個数 $N 」$ を求め，これらの積 $S T$ を 以下のように求める

$$
S T=D \times M \times Q
$$

3. 画像を変えて, (1) および (2) を繰り返し行い, $S T$ の平 均值 $\overline{S T}$ と標準偏差 $\sigma_{S T}$ を算出する. 平常時におけるフ ローのモデルとして保持する。

3.2 識別末末知画像における暴れ検出は, 次のようにし て行う.

1. 未知画像間の全点で, SAD ブロックマッチングによりフ ローベクトルを求める．その際，マッチングレベルの低 いフローは破棄する。

2. 後述のテクスチャ背景差分によって抽出された変化領域 中に㧍いて，大きさが非零のフローベクトルに対し，式 1 より $S T$ を求める.

3. 学習済のフローモデルにより, $S T$ を学習モデルにより正 規化した值 $P S T$ を以下のように求める.

$$
P S T=(S T-\overline{S T}) / \sigma_{S T}
$$

4. 正規化された統計量 PST が閾值を越えれば暴れとみなす

\section{4. 人物有無検知アルゴリズム}

人物の閉じ込めなどを検知するためには，まずエレベーター 内に人物が存在するかどうかを検知することが必要となる。本 論文では，空付きを含む通常のエレベーターにおいて人物を 高精度に検出する手法を提案する。

空を除く部分は通常変化しない背景であり，人物や物体の 有無は背景差分によって検出することが可能である. しかし， エレベーター内の照明は照度が不安定な場合があり，また力 メラのゲインも一定ではないため，画像の輝度が大きくふら つく場合がある．さらに，空付きエレベーターでは外光の影 響を受けてかご内の輝度が大きく変動することがある．例え ば，空付きエレベーターの空から直射日光が入ると Fig.4の ように一部の輝度が通常より大幅に高い画像となる。

したがって，ガウシアンモデルを当てはめるような通常の 背景差分では，一時的な直射日光などに対忘することができ ず，誤検知となってしまう，このことから本論文では照明変 動に強いテクスチャ背景差分方式 ${ }^{(8)}$ を採用した。本方式は画 像を格子状のブロックに分割し，それぞれの格子点での背景 および入力画像のテクスチャをそれぞれべクトル化して，そ のベタトル同士の距離によって背景と前景を分離する：本手 法ではエッジやテクスチャの変化さえなければ，大きな照明 変動があっても誤検知することはない。

本手法を用いれば人物の有無検知は非常に単純なアルゴリ ズムで実現できる，画像全体の面積を $A$ ，テクスチャ背景差 分により検出された前景の面積を $A_{N}$ とすれば，以下の条件

$$
A_{N} / A>T_{A}
$$

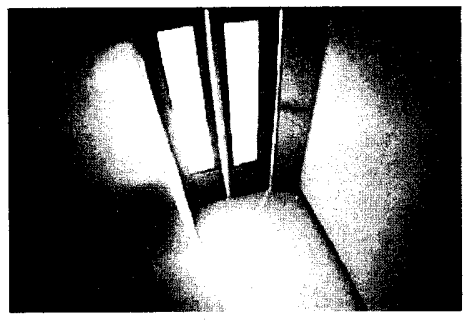

Fig. 4 ITV camera image of window door elevator with sunlight.

Table 2 Scenario of violent action scene

\begin{tabular}{|l|}
\hline Rob a bag. \\
\hline Rob a bag after panching. \\
\hline Rob a bag after pouncing with a hammer. \\
\hline Rob a wallet after threating with a knife. \\
\hline Rob a bag after pouncing with a knife. \\
\hline Rob a bag while getting a full nelson. \\
\hline Becomes the quarrel of an exchange of blows after the dispute. \\
\hline Run away after trying to rob a bag. \\
\hline Run away after be offenced by self-diffence splay. \\
\hline Run away after struggling. \\
\hline Run away after alarm emitted. \\
\hline
\end{tabular}

を満たすとき人物有りとみなす。ここで $T_{A}$ は定数である。な お，人物有無検知は人物有りを見逃がすと致命的なため， $T_{A}$ は通常小さくとる.

\section{5. 実 験 結 果}

5.1 暴れ検知 Fig.5 に示す 8 種類のかご内 ITV カメラ 映像を用いて実験を行った。図を見て分かるように，これら の映像は, 意匠の異なる 4 種類のエレベーターの 2 䇢所から それぞれ撮影されたものである，各映像には，平常時の利用 シーンと，専門の役者によって再現された典型的な犯罪シー ン (Table2) が写っている. また評価に際して，256 階調の濃 淡画像に変換し，画像を $80 \times 60$ 画素サイズに縮小した。 才 プディカフローは SAD ブロックマッチングで求めた.

Fig.6に，本アルゴリズムの性能評価結果として，闇值を 徐々に変化させて描いた ROC 曲線を示す。縦軸は暴れ状態を 見逃した割合 (false rejection), 横軸は平常状態を暴れと誤つ て検出した割合 (false acception) を表している．数\%の過鄱 検出時に $85 \%$ の正検出率を達成しており，実用的な結果と なっている.

5.2 人物有無検知 空無しおよび空付きエレベーターを それぞれ 1 基ずつ実際に稼働させ，1日間，通常の乗降を行 う．これをかご内 ITV カメラで撮像し，各時刻の人物有無の 真值データを作成すると共に, 提案アルゴリズムにて自動検 知する。これらの結果を比較して過剩検知 (false acception) お よび見逃し (false rejection) をカウントし，その割合を 2 軸の グラフに ROC 曲線として示した。

Fig.7(a),(b)にそ扎ぞれ空無し, 空付きエレベーターでの上 


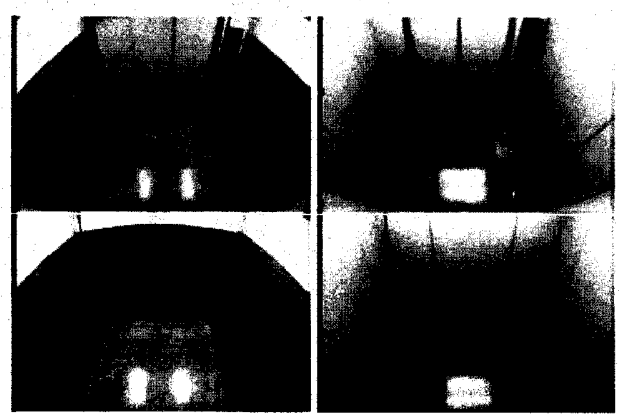

(a) large (b) bright

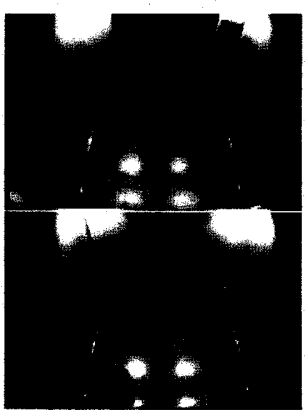

(c) with mirror

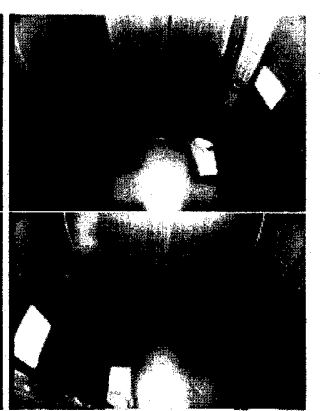

(d) special designed wall

Fig. 5 Overview of each elevator car(upper: overview from back side, lower: overview from door side).

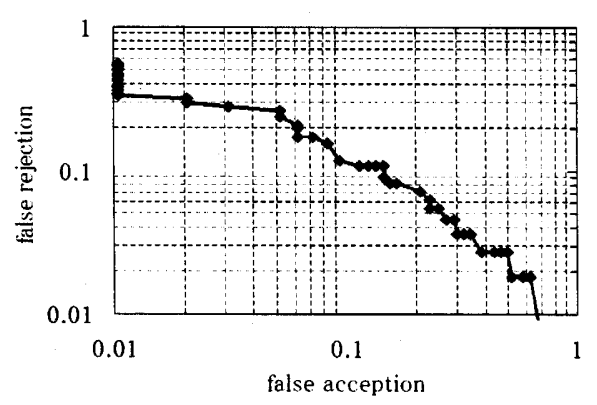

Fig. 6 ROC curve of violent action detection.

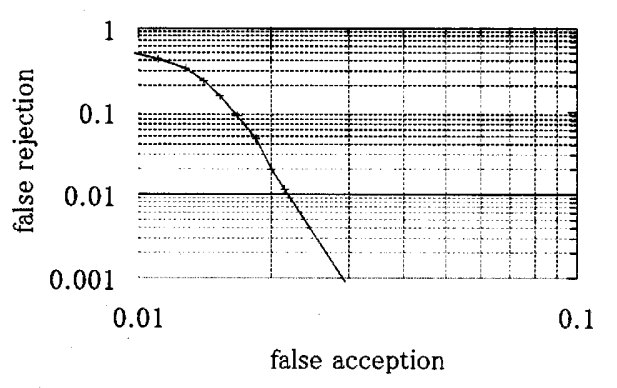

(a) with non-window door

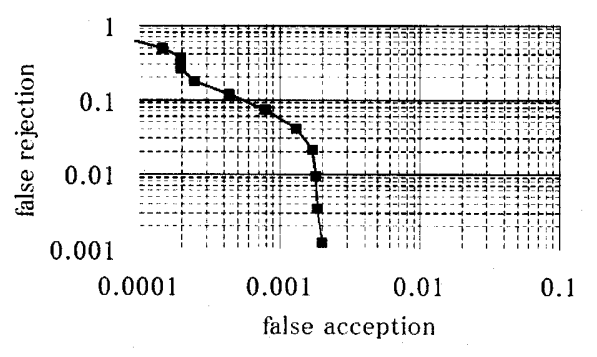

(b) with window door

Fig. 7 ROC curves of object detection.

記 ROC 曲線を示す．これらの結果から分かるのは，検知率 99\%以上 (見逃し 1\% 未満)の実運用域において，本手法が䛊 検知約 $1 \%$ 前後となっていることである. 実際には時系列上 の複数の検知結果を見て人物有無を総合的に判断するため, $1 \%$ 程度の誤検知は無視し得る程度と考えられる.

\section{6. お わり に}

本論文では，エレベーターかごへの適用を目的とした，動 きの統計モデルに基づく暴れおよび人物有無検知システムに ついて述べた．まず暴れ動作時のオプティカルフローにばら つきが見られることを検証した. そしてフローベクトルの向 きと大きさのばらつき，および個数を評価することで暴れを 検出するアルゴリズムを示した．さらに空付きエレベーター などにも応用できる人物有無検知アルゴリズムを示した．実 験では, 犯罪事例を再現した模擬映像に対する暴れ検知の有 効性, および空無し, 空付きエレベーターでの人物有無検知 の有効性を確認した. 今後の課題としては, さらに多様な犯 罪に対する検出システムの実現が挙げられる.

\section{文献}

（1）社団法人日本エレベータ協会, “協会速報,” 2000 年 1 月 号-2003 年 3 月号, Web サイト http://www.n-elekyo.or.jp/.

(2) Ankur Datta, Mubarak Shah and Niels Da Vitoria Lobo, "Person-on-Person Violence Detection in Video Data," Proc. of ICPR, pp.433-438, 2002.

(3) Nebojsa Jojic, Matthew Turk and Thomas S. Huang, "Tracking Self-Occluding Articulated Objects in Dense Disparity Maps," Proc. of ICCV, Vol.1, pp.123-130, 1999.

(4) 高田広章, “組达みシステム開発技術の動向,”システム/ 制御/情報, Vol.45, No.3, pp.115-117, 2001.

(5) 高橋勝彦, 関進, 小島浩, 岡隆一, “ジェスチャー動画像の スポッティング認識,” 信学論 D-II, Vol.J77-D-II, No.8, pp.1552-1561, 1994.

（6）畠直志, 岩井儀雄, 谷内田正彦, “動き情報と情報圧縮を 用いたロバストなジェスチャ認識手法,”信学論 D-II, Vol.J81-D-II, No.9, pp.1983-1992, 1998.

（7）長屋茂喜, 宮武孝文, 藤田武洋, 伊藤渡, 上田博唯, “時 間相関型背景判定法による移動物体検出,”信学論 D-II, Vol.J79-D-II, No.4, pp.568-576, 1996.

(8) 松山隆司, 和田俊和, 波部斉, 棚橋和也, “照明変化に碩健 な背景差分,” 信学論 D-II, Vol.J84-D-II, No.10, pp.2201$2211,2001$. 